\title{
Emergency Evacuation of Hazardous Chemical Accidents Based on Diffusion Simulation
}

\author{
Jiang-Hua Zhang, Hai-Yue Liu, Rui Zhu, and Yang Liu \\ School of Management, Shandong University, Jinan, Shandong, China \\ Correspondence should be addressed to Jiang-Hua Zhang; zhangjianghua@sdu.edu.cn
}

Received 16 June 2017; Accepted 7 November 2017; Published 14 December 2017

Academic Editor: Dimitri Volchenkov

Copyright (C) 2017 Jiang-Hua Zhang et al. This is an open access article distributed under the Creative Commons Attribution License, which permits unrestricted use, distribution, and reproduction in any medium, provided the original work is properly cited.

\begin{abstract}
The recent rapid development of information technology, such as sensing technology, communications technology, and database, allows us to use simulation experiments for analyzing serious accidents caused by hazardous chemicals. Due to the toxicity and diffusion of hazardous chemicals, these accidents often lead to not only severe consequences and economic losses, but also traffic jams at the same time. Emergency evacuation after hazardous chemical accidents is an effective means to reduce the loss of life and property and to smoothly resume the transport network as soon as possible. This paper considers the dynamic changes of the hazardous chemicals' concentration after their leakage and simulates the diffusion process. Based on the characteristics of emergency evacuation of hazardous chemical accidents, we build a mixed-integer programming model and design a heuristic algorithm using network optimization and diffusion simulation (hereafter NODS). We then verify the validity and feasibility of the algorithm using Jinan, China, as a computational example. In the end, we compare the results from different scenarios to explore the key factors affecting the effectiveness of the evacuation process.
\end{abstract}

\section{Introduction}

With the development of the world economy, hazardous chemicals have become important materials in industrial and agricultural production, national defense construction, and the daily life of people. However, in recent years, serious accidents caused by hazardous chemicals have occurred with increasing frequency in the world. For example, on February 7, 2010, an acrylate leakage accident occurred at a chemical company in Panyu, Guangzhou, and thousands of nearby villagers were evacuated urgently. On April 17, 2013, a fertilizer plant in the American region of western Texas exploded, setting at least 10 buildings on fire, causing 35 casualties and injuring more than 160 people. On July 19, 2014, an especially serious road traffic and deflagration accident occurred on the Shanghai-Kunming expressway in Shaoyang, Hunan, causing 54 casualties, injuring 6 people, and creating a direct economic loss of 53 million yuan. On November 15, 2014, a methanethiol leakage accident occurred at an American DuPont factory, which was located in the southeastern Houston area, causing 4 casualties, injuring 1 person, and affecting many surrounding residents. On August 12, 2015, huge explosions caused by improper storage of chemicals occurred in Tianjin and claimed the lives of 165 people and caused a directed economic loss of 6.8 billion yuan. Due to the toxicity and diffusion of hazardous chemicals, these accidents not only caused casualties and economic losses but also polluted the environment, causing serious social panic and traffic jams. Emergency evacuation after hazardous chemical accidents is an effective means to reduce the harm. In addition, the information technology is developing rapidly in recent years, so we can use these technologies to do some simulation experiences which can have a positive impact on emergency evacuation. Therefore, using advanced technologies to study the emergency evacuation following hazardous chemical accidents is very necessary.

Research on the emergency evacuation problem first appeared in the 1960s. Evacuation models can be mainly divided into two categories: mathematical models based on network optimization and simulation models. Hamacher and Tjandra (2002) [1] reviewed the mathematical models based on network optimization. Murray-Tuite and Wolshon (2013) [2] presented a review of highway-based evacuation modeling and simulation and its evolution over the past 
decade. In recent years, many scholars have studied the emergency evacuation problem using different methods. Cova and Johnson (2003) [3], Xie and Turnquist (2011) [4], and Fang et al. (2013) [5] studied the lane-based evacuation network optimization problem. Lim et al. (2012) [6], Hadas and Laor (2013) [7], and Sheu and Pan (2014) [8] focused on the development of models for the design of an optimal network for emergency evacuation. Duanmu et al. (2012) [9], Fang et al. (2013) [5], Uchida (2014) [10], and Zhang and Chang (2014) [11] established evacuation models considering travel demand distribution problems and risk-averse drivers' route choices. In addition, some scholars considered modeling evacuation networks based on the vulnerability of path networks, for example, Snelder et al. (2012) [12], Chen et al. (2012) [13], and Bell et al. (2014) [14]. And GIS-based DSS was developed to bring the emergency evacuation planning into implementation by some scholars, for example, Zhang et al. (2016) [15].

Regarding the study of simulation models, Yin et al. (2014) [16] presented an agent-based travel demand model for simulating hurricane evacuations, which was capable of generating comprehensive household activity and travel plans. The system considered six typical evacuation decisions: evacuate/stay, accommodation type choice, evacuation destination choice, mode choice, vehicle usage choice, and departure time choice. Zhang et al. (2012) [17] introduced a data simulation model to express the topological and geometrical relationships of a building's inner structures to determine the optimal routes for rescue and evacuation in a complex building. Nishino et al. (2012) [18] introduced a proposed simulation method that calculated the probability that the ratio of burned-down buildings or fire fatalities in a district would exceed a threshold within a given time period after an earthquake. Alvear et al. (2014) [19] used computer modeling and simulation to explore the impact that crew procedures had on evacuating two high-speed trains under different fire scenarios. Wu and Huang (2015) [20] simulated the dynamics of the evacuees and derived the evacuation times of a high-rise building by using the control volume model. C. Wang and J. Wang (2017) [21] presented an extended floor-field (FF) model combined with risk factors for emergency evacuation and they validated model through numerical simulations with specific room structures.

Many scholars have conducted very fruitful studies on the building evacuation problem from different angles. Pursals and Garzón (2009) [22], Zhang et al. (2013) [23], and Ronchi et al. (2014) [24] formulated the building evacuation problem and generalized the evacuation function to incorporate evacuation routes using Monte Carlo and other stochastic methods. Wu and Chen (2012) [25] used a 3D geometric network model (GNM) and the Dijkstra algorithm to consider smoke movement during different times of a building fire. Bhushan and Sarda (2013) [26] introduced ladder exits in the building evacuation problem that were created by placing ladders at possible openings in a building. They modified the existing network flow based on an evacuation planning model to incorporate ladders and presented three different optimization formulations to model various scenarios.
Siddiqui et al. (2012) [27] and Verma et al. (2012) [28] studied the evacuation problem of hazardous materials, in which Siddiqui et al. (2012) [27] proposed a computational fluid dynamics- (CFD-) based model for indoor risk assessment that considered accidental release of a sustained, small, undetected leak of a dense toxic gas (chlorine) in an industrial indoor environment. Li et al. (2012) [29], Najafi et al. (2013) [30], and Bish and Sherali (2013) [31] studied largescale regional evacuations caused by hurricanes, wildfires, or earthquakes. They studied the demand-based strategies of aggregate-level staging and routing to structure the evacuation demand, both with and without congestion and then designed two heuristics. Shen et al. (2015) [32] established a conceptual decision support system for toxic leakage in a chemical industrial park and reported a method of determining the scope of evacuation following a leakage accident.

As seen from above, the existing literature on emergency evacuation mostly focuses on disasters such as fires and hurricanes. However, there are few studies of emergency evacuations following hazardous chemical accidents. As everyone knows, disasters and accidents of different types have different characteristics. Thus, emergency evacuation plans should be made according to the different characteristics of specific issues. Hazardous chemical accidents are different from other accidents because the toxicity and the diffusion of chemicals make the hazardous chemicals' concentration change with the passage of time, weather conditions, and wind speed. Therefore, it is very necessary to research the emergency evacuation of hazardous chemical accidents.

In this paper, we focus on the emergency evacuation following hazardous chemical accidents. We build a mixedinteger programming model and design a heuristic algorithm based on network optimization and diffusion simulation (hereafter NODS). The distinguishing contributions of the paper are as follows. First, according to the assumptions of the hazardous chemical accident, we simulate the dynamic change of the hazardous chemicals' concentration and the range of influence of the hazardous chemical accident with a MATLAB program. Second, considering the toxicity and the diffusion of hazardous chemicals, we build a mixed-integer programming model that aims to minimize the concentration of hazardous chemicals to which people are exposed in the entire evacuation process. Then, a heuristic algorithm is designed to solve the model. Finally, a computational example based on an incident in Jinan shows the validity and feasibility of our algorithm, and we explore the key factors affecting the evacuation process through different scenarios.

The remainder of the paper is organized as follows. Section 2 introduces the physicochemical property of chlorine and the results of simulation. In Section 3, we introduce the mixed-integer programming model and the NODS algorithm. The computational example is carried out in Section 4. Finally, we conclude the work with some recommended future directions in Section 5.

\section{Diffusion Simulation}

2.1. Physicochemical Property of Chlorine. This paper considers common chlorine for the research of hazardous chemical 
accidents and emergency evacuation. At normal temperature and pressure, chloride is a type of gas with a yellow-green color and an irritating odor. It will transform into a liquid when the surrounding air pressure is more than $709 \mathrm{kPa}$. The molecular weight of chlorine is 70.91 . Its melting point is -101 degrees Celsius, and its boiling point is -34.5 degrees Celsius. Its gas density is $3.21 \mathrm{~g} / \mathrm{L}$, and its relative vapor density is 2.5 (air is 1). Chloride poses dangers from combustion and explosion, and it can be used as an auxiliary combustion agent. Most general fuel can burn in the presence of chlorine gas, and flammable gas or vapor can form explosive mixtures with chlorine gas. Moreover, chloride can react with water, producing toxic hypochlorous acid and hydrochloric acid.

In daily production and life, chlorine has a wide range of uses. It is used not only in the manufacture of vinyl chloride, allyl chloride, and epichlorohydrin but also as a disinfectant in the process of water treatment. On the other hand, chlorine is a highly toxic and hazardous chemical. Inhalation of high concentrations of chlorine gas can lead to death, and chlorine is one of the key hazardous chemicals in state supervision.

Chlorine causes serious harm to the human body, for it can irritate the eyes, nose, throat, upper respiratory tract, and other body parts. When the mass concentration is higher than $1 \sim 6 \mathrm{mg} / \mathrm{m}^{3}$, it will cause significant irritation to humans. A concentration of $12 \mathrm{mg} / \mathrm{m}^{3}$ is unbearable for most people. A concentration of $90 \mathrm{mg} / \mathrm{m}^{3}$ can cause acute coughing. A concentration of $120 \sim 180 \mathrm{mg} / \mathrm{m}^{3}$ is very dangerous and can cause acute pulmonary edema and pneumonia in 30 $60 \mathrm{~min}$. A concentration of $300 \mathrm{mg} / \mathrm{m}^{3}$ can cause fatal injury. A concentration of $3000 \mathrm{mg} / \mathrm{m}^{3}$ can cause immediate respiratory failure, and a "stroke death" will occur. When the concentration is more than $30000 \mathrm{mg} / \mathrm{m}^{3}$, general viral gas masks lose their protective effect.

Under normal temperature and pressure, liquid chlorine can be compressed and stored in liquefied form. Once it leaks into the atmosphere, it will expand and gasify under normal pressure, spreading to occupy a large space. In this paper, the liquid chlorine leakage is caused by an accident following damage to a container filling valve. After the accident, changes in the state of liquid chlorine can be divided into the following three processes.

(1) Liquid chlorine leaks: pressurized liquid chlorine is leaked to the environment at normal temperature and pressure.

(2) Liquid chlorine flashes: in a serious accident, liquid chlorine is quickly leaked to the surrounding atmosphere. Because of the pressure, a part of the liquid chlorine quickly converts into gas. The process of transitioning from the gasliquid equilibrium under high pressure into the gas-liquid equilibrium under normal pressure is named the flash. The ratio of direct evaporation to liquid is also called the flash rate $F_{\text {vap: }}$

$$
F_{\text {vap }}=\frac{C_{p}(\Delta T)}{L} .
$$

In the formula, $F_{\text {vap }}$ is the flash rate, $C_{p}$ is the mean specific heat of gas $(\mathrm{kJ} / \mathrm{kgK}), \Delta T$ is the temperature difference between the temperature and the boiling point in the container under the environmental pressure $(\mathrm{K})$, and $L$ is the heat of vaporization $(\mathrm{kJ} / \mathrm{kg})$. Because the mean specific heat of liquid chlorine is $0.98 \mathrm{~kJ} / \mathrm{kgK}$, the boiling point is -34.5 degrees Celsius, and the heat of vaporization is $289 \mathrm{~kJ} / \mathrm{kg}$, the flash rate of liquid chlorine is approximately $20 \%$ under normal atmospheric temperature ( 25 degrees Celsius). When liquid chlorine leaks, the liquid which evaporates directly will form clouds in the form of tiny smoke and mix with air, which then absorbs heat and evaporates. If the heat passed from air to the liquid smoke is not enough to cause evaporation, the smoke will condense into droplets and land on the ground, forming a liquid pool. According to experience, when $F>$ 0.2 , usually it will not form a liquid pool. This paper assumes that when the percentage of liquid chlorine leakage is $20 \%$, it will directly turn into gas.

(3) The diffusion of gaseous chlorine: liquid chlorine diffuses in the air after the gasification.

In this paper, we select the basic equation of fluid mechanics Bernoulli equation to describe the liquid chlorine leakage rate. To depict gas diffusion behavior after liquid chlorine flashes, the paper uses the Gaussian smoke model, which is the most widely used model of gas diffusion. The leakage model, the diffusion parameter, and the Gaussian smoke cloud model have been introduced in detail, respectively, in literatures [33] and [34]. Due to word constraints, they are not discussed further in this paper.

2.2. Simulation Calculation. The valve of a tank car which is loaded with 20 tons' liquid chlorine has been completely damaged and the liquid chlorine leaks continuously. The valve diameter is $25 \mathrm{~mm}$, leakage is $50 \%$, and the wind speed is 5.4 meters/seconds. The key MATLAB codes for the simulation calculation are shown in Algorithms 1, 2, and 3.

According to the liquid chlorine concentration, the affected areas can be divided into lethal circle $\left(3000 \times 10^{-6}\right)$, semilethal circle $\left(300 \times 10^{-6} \sim 3000 \times 10^{-6}\right)$, and injury circle $\left(30 \times 10^{-6} \sim 300 \times 10^{-6}\right)$ which will lead to death, disability, and injury, respectively. The concentration diffusion of the lethal circle, the semilethal circle, and the injury circle is shown in Figure 1 and Table 1.

Table 1 shows that when the valve of the tank car loaded with 20 tons of liquid chlorine has been completely damaged and liquid chlorine leaks continuously, the valve diameter of the tank is $25 \mathrm{~mm}$, the leakage is $50 \%$, and the wind speed is 5.4 meters/second; the lateral distances of the lethal circle, the semilethal circle, and the injury circle are $36 \mathrm{~m}, 99 \mathrm{~m}$, and $144 \mathrm{~m}$, respectively. The maximum distance at which people will be injured in a downwind direction is $651 \mathrm{~m}$. Thus, we should evacuate people in the affected area to locations $651 \mathrm{~m}$ from the accident in the downwind direction and $144 \mathrm{~m}$ from the accident in the longitudinal distance to minimize casualties. We obtain the influenced area by simulation, as shown in Figure 2. The area of influence is $252,210 \mathrm{~m}^{2}$.

\section{Model and Algorithms}

In this paper, we specifically study emergency evacuation problems following hazardous chemical accidents. General 
(1) \% Calculate the liquid chlorine leak rate $C$ in every moment, the unit is $\mathrm{kg} / \mathrm{s}$

(2) $\% P$ represents the pressure inside the liquid chlorine tank trucks

(3) $\% g$ represents the gravitational acceleration

(4) \% Cd represents the liquid leakage coefficient

(5) $\% A$ represents the fissure area

(6) \% $P 0$ represents the environmental pressure

(7) $\% h$ represents the height of the valve from the ground

(8) function $C=\operatorname{get} Q \operatorname{perMin}(P)$

(9) $\quad P 0=1.0 e+005$;

(10) $g=9.8$;

(11) $h=0$;

(12) $C d=0.5$;

(13) $A=p i * 0.025^{\wedge} 2$;

(14) $\mathrm{rol}=1.468 e+003$;

(15) $C=C d * A * \operatorname{rol} * \operatorname{sqlt}(2 *(P-P 0) / r o l+2 g h)$;

Algorithm 1: GetOperMin $(P)$.

(1) \% Calculate the concentration on some point at some moment, the unit is $\mathrm{mg} / \mathrm{s}$

(2) $\% d x, d y, d z$ represent the diffusion coefficient on the $x, y, z$ axis respectively

(3) $\% x, y, z$ represent the coordinate values on the $x, y, z$ axis

(4) $\% t$ represents the diffusion time, the unit is $\mathrm{s}$

(5) $\% u$ represents the average wind speed, the unit is $\mathrm{m} / \mathrm{s}$

(6) function $c=$ getConcentrationPerQ $(u, t, x, y, z)$

(7) $\quad d x=0.425809 * a b s(x) .^{\wedge} 0.901074$;

(8) $\quad d y=d x$;

(9) $d z=0.0799904 * a b s(x) \wedge 1.12154$;

(10) $\quad c=\exp \left(-(x-u * t)^{\wedge} 2 /\left(2 * d x^{\wedge} 2\right)-y^{\wedge} 2 /\left(2 * d y^{\wedge} 2\right)-z^{\wedge} 2 /\left(2 * d z^{\wedge} 2\right)\right) /\left(\operatorname{sqrt}(2) * p i^{\wedge} 1.5 * d x * d y * d z\right)$;

(11) $\quad c(i \operatorname{snan}(c))=0$;

Algorithm 2: GetConcentrationPerQ $(u, t, x, y, z)$.

emergency evacuation problems consider mostly how to evacuate all people to safe areas with the fastest speed or in the shortest time. Nevertheless, the biggest difference between emergency evacuation problems following hazardous chemical accidents and other evacuation problems is that the goal of emergency evacuation problems following hazardous chemical accidents is to minimize damage to people cause by the hazardous chemicals. This paper considers the emergency evacuation problem between a specific evacuation source point and a specific end point after a hazardous chemical accident in which the concentration of hazardous chemicals at each point changes at discrete points in time.

\subsection{Symbols and Decision Variables}

$G=(V, E):$ traffic network diagram

$V$ : point set; points represent path intersections, including the evacuation source point and end point; $|V|=N$, in which the evacuation source point is 1 and the end point is $N$

$V S$ : evacuation source point set

$V M$ : middle point set

$V E$ : evacuation end point set
$E=\left(e_{i j}\right)$ : the set of an arc, where $e_{i j}$ represents the arc between point $i$ and $j$

ES: starting arc set

$E E$ : ending arc set

ICS: the initial number of people who are waiting to be evacuated at the evacuation source point

$\mathrm{MCN}_{i}$ : the maximum capacity of point $i$

$\mathrm{MC}_{i j}$ : the maximum capacity of arc $e_{i j}$

$\mathrm{CN}_{i}(t)$ : the capacity of point $i$ at time

$C_{i j}(t)$ : the capacity of arc $e_{i j}$ at time $t$

$t_{i j}$ : the length of time when travelling through arc $e_{i j}$

$\operatorname{PPM}_{i j}(t)$ : the cumulative concentration on the arc of point $i$ to point $j$ at time $t$

$\mathrm{Con}_{i}(t)$ : the concentration on point $i$ at time $t$

$T_{0}$ : the beginning time of evacuation from the evacuation source point

$P^{k}$ : the $k$ th path of the evacuation source point

$f^{k}$ : the flow of $P^{k}$, which is the $k$ th path of the evacuation source point 


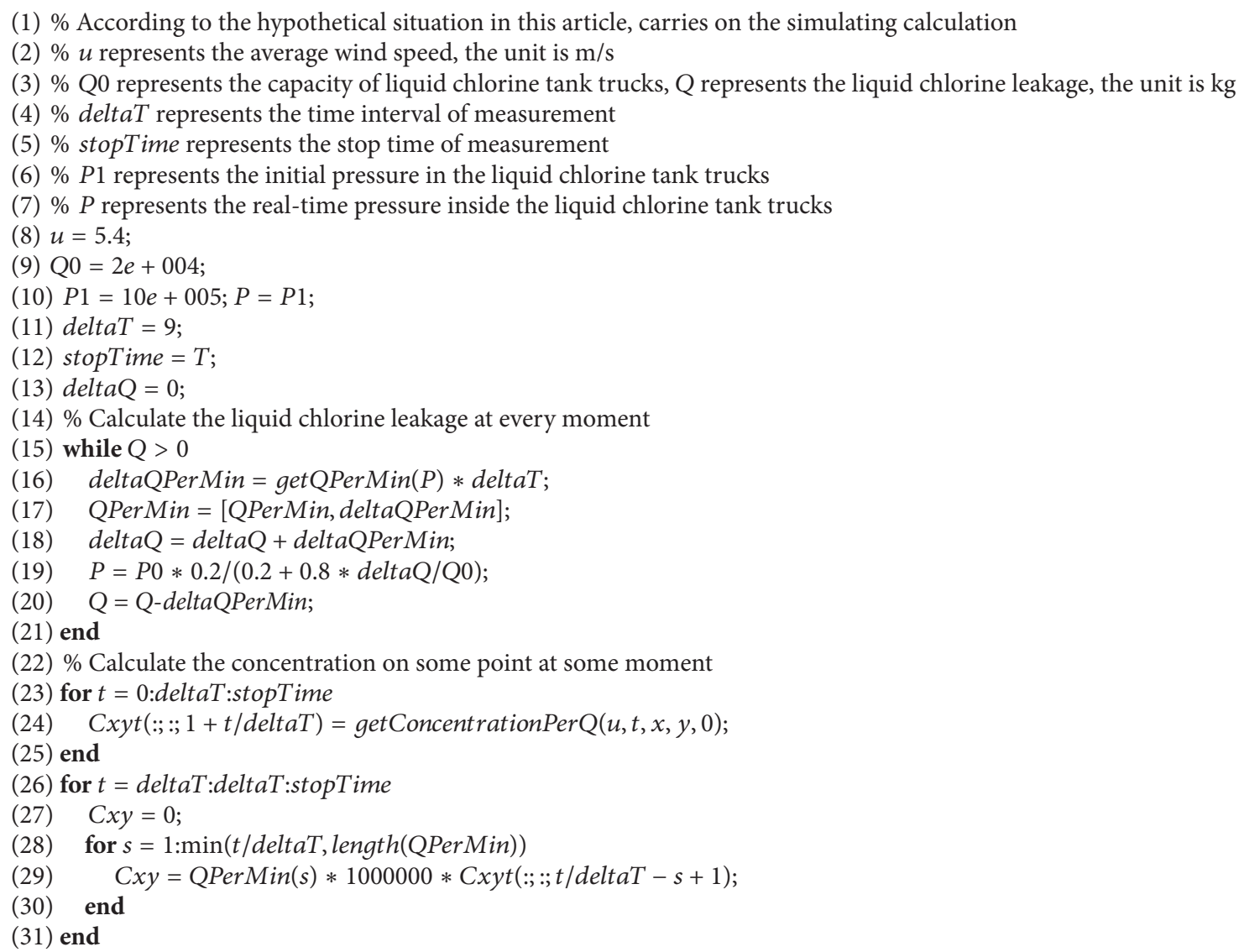

Algorithm 3: The simulating calculation (part).

$x_{i j}(t)$ : the number of people who enter arc $e_{i j}$ at time $t$ and arrive at point $j$ at time $t+t_{i j}$

$y_{i}(t)$ : the number of people on point $i$ at time $t$

$z_{i j}(t)$ : the number of all people on the $\operatorname{arc} e_{i j}$ at time $t$.

3.2. Modeling. The mixed-integer programming problem is written as follows, selecting point 1 as the evacuation source point and point $N$ as the end point:

$$
\begin{array}{ll}
\min & \sum_{e_{i j} \in E} x_{i j}(t) \cdot \operatorname{PPM}_{i j}(t)+\mathrm{CN}_{1}(t) \cdot \operatorname{Con}_{1}(t) \\
\text { s.t. } & y_{1}(0)=\mathrm{ICS} \\
& y_{i}(0)=0 \quad \forall i \in V \backslash\{1\} \\
& x_{i j}(0)=0 \quad \forall i, j \in V \\
& y_{i}(t) \leq \mathrm{MCN}_{i} \quad \forall i \in V \\
& x_{i j}(t) \leq \operatorname{MC}_{i j} \quad \forall i, j \in V \\
& z_{i j}(t)=\sum_{t_{z} \in T_{i j}} x_{i j}\left(t_{z}\right) \quad \forall i, j \in V
\end{array}
$$

$$
\begin{aligned}
& \sum_{n_{i} \in V} y_{i}(t)+\sum_{e_{i j} \in E} z_{i j}(t)=\mathrm{ICS} \\
& y_{i}(t)-y_{i}(t-1) \\
& =\sum_{k \in \operatorname{pred}(i)} x_{k i}\left(t-t_{k i}\right)-\sum_{j \in \operatorname{succ}(i)} x_{i j}(t)
\end{aligned}
$$

$$
y_{i}(t)=y_{i}(t-1) \sum_{e_{i j} \in E S} x_{i j}(t) \quad \forall i \in V S
$$

$$
y_{i}(t)=y_{i}(t-1)+\sum_{e_{i j} \in E E} x_{i j}\left(t-t_{i j}\right) \quad \forall i \in V E
$$

$$
\begin{aligned}
& x_{i j}(t) \geq 0, \\
& y_{i}(t) \geq 0, \\
& z_{i j}(t) \geq 0,
\end{aligned}
$$

where $\operatorname{pred}(i)=\{j \mid(j, i) \in E\}, \operatorname{succ}(i)=\{j \mid(i, j) \in E\}$, and $T_{i j}=\left\{t_{e} \mid t-t_{i j}+1 \leq t_{e} \leq t,(i, j) \in E\right\}$. The objective function (2) states that the goal of the problem is to minimize the concentration of hazardous chemicals to which all people who are waiting to be evacuated are exposed during the entire 


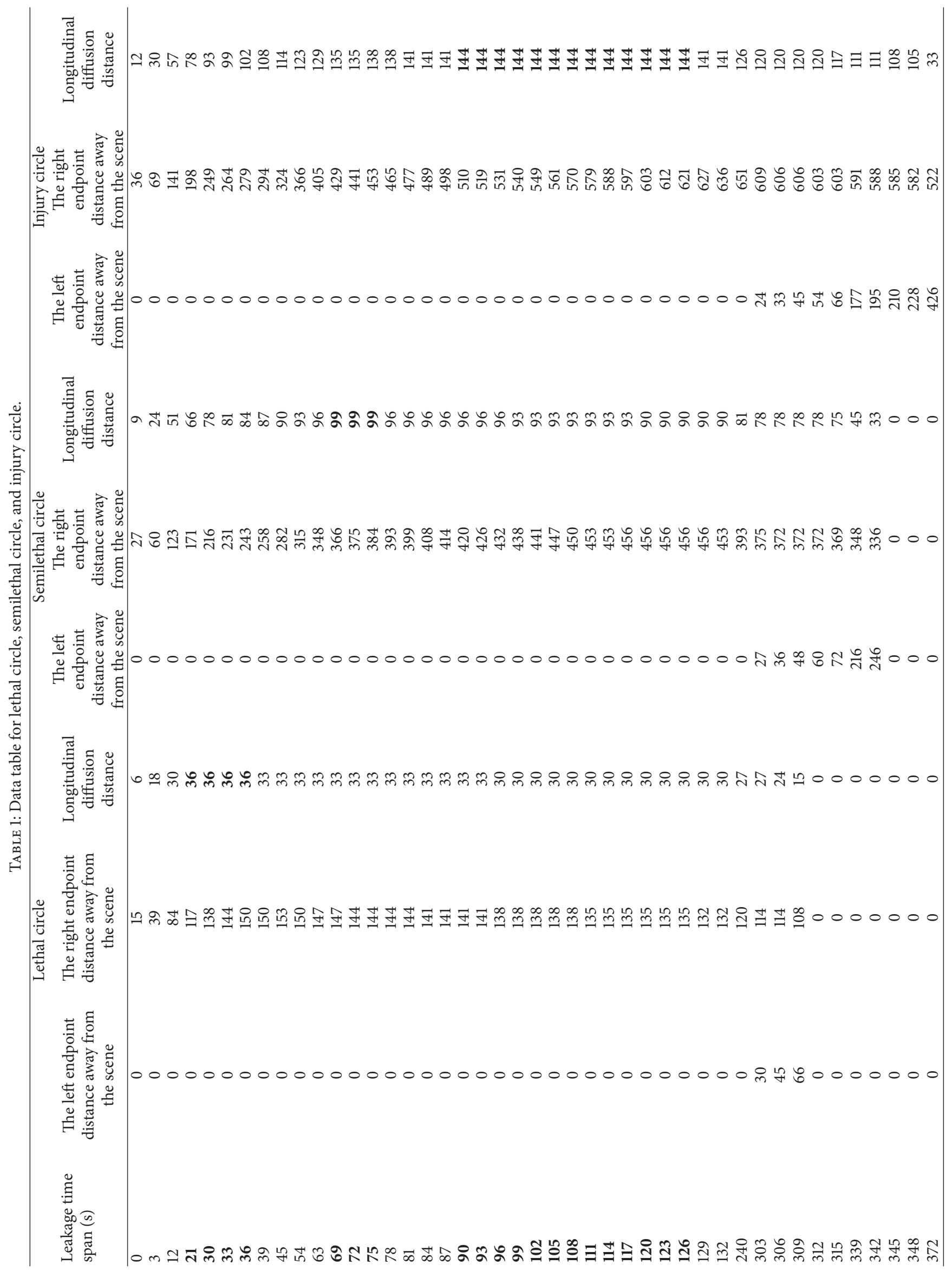




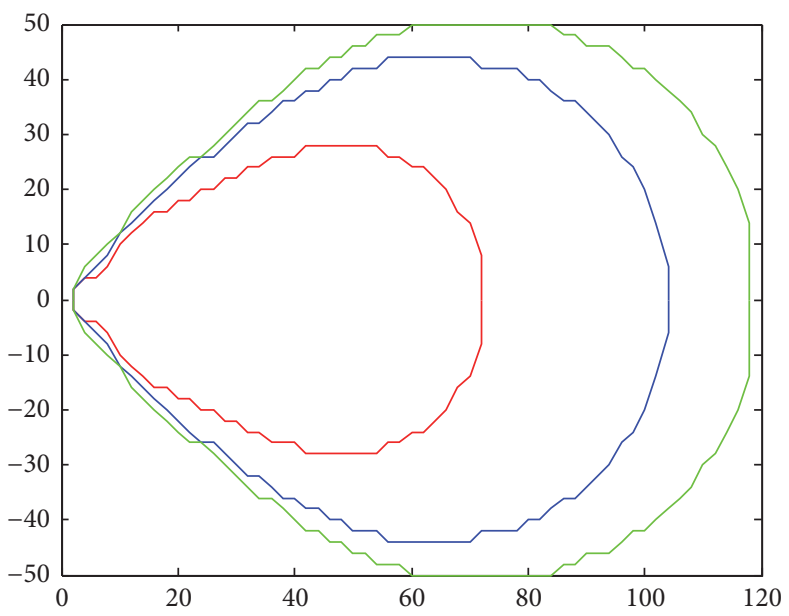

(a) The concentration diffusion figure when the leakage has lasted for 12 seconds

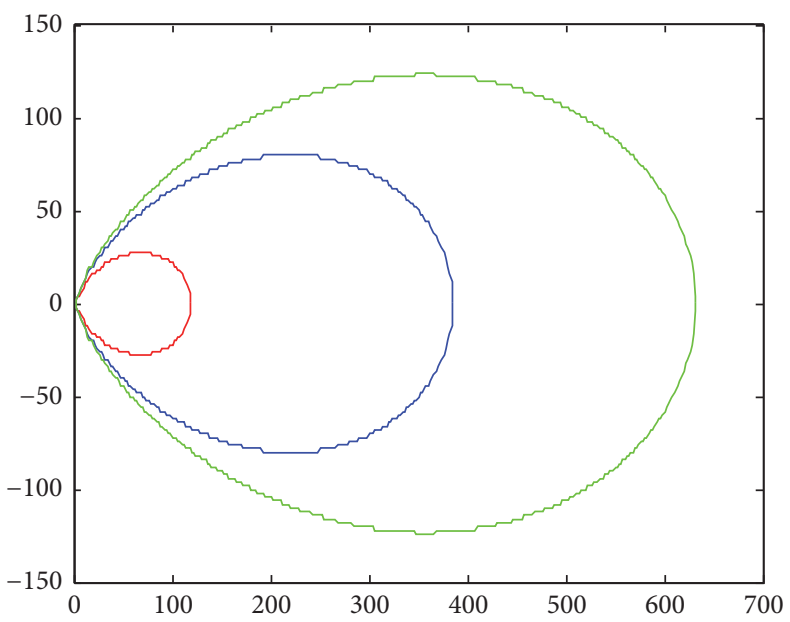

(c) The concentration diffusion figure when the leakage has lasted for 270 seconds

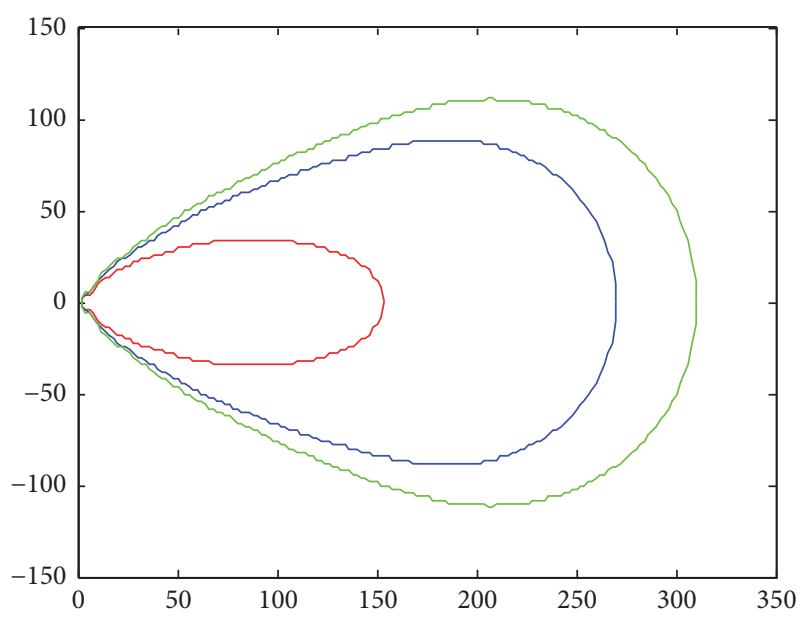

(b) The concentration diffusion figure when the leakage has lasted for 45 seconds

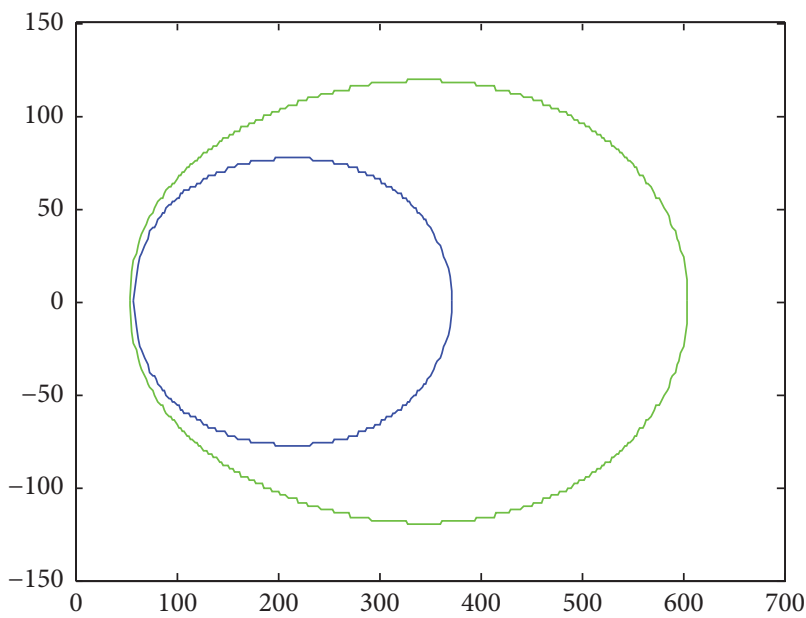

(d) The concentration diffusion figure when the leakage has lasted for 315 seconds

FIGURE 1: The concentration diffusion with different leakage time.

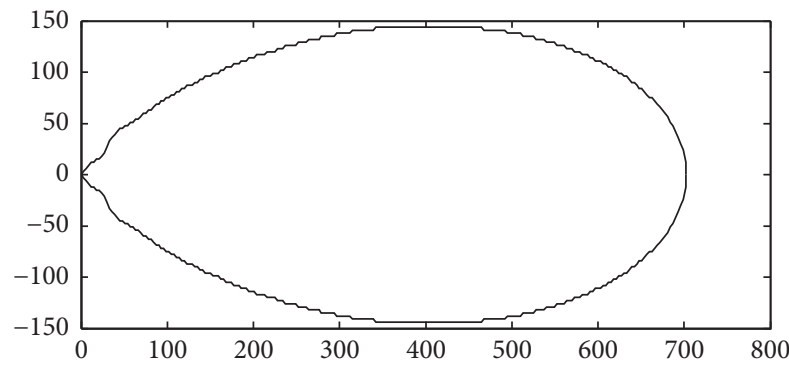

FIGURE 2: The influenced area of liquid chlorine leakage.

evacuation process. Constraint functions (3), (4), and (5) represent the initial state of the whole evacuation network. Equations (6) and (7) represent the capacity limit constraints of the point $i$ and $\operatorname{arc} e_{i j}$ at time $t$. Equation (8) represents the conservation of flow on the arc $e_{i j}$. Equation (9) represents the conservation of the evacuation crowd in the whole evacuation network at time $t$. Equation (10) represents the conservation of flow at the middle point $i$. Equation (11) represents the conservation of flow at evacuation source point. Equation (12) represents the conservation of flow at the end point. Equation (13) represents the fact that the decision variables must be nonnegative.

3.3. Algorithm. Since evacuation problems are NP-hard problems and there is no polynomial algorithm, we design the NODS algorithm that can calculate evacuation plans following hazardous chemical accidents based on network optimization and diffusion simulation satisfying the constraints and objectives of the above mathematical model. The algorithm introduces a concept of $K$ shortest paths, which refer to the 1 st, 2 nd, $\ldots, K$ th shortest paths from evacuation source point to the end point. In this article, $K$ shortest paths refer to the path corresponding to the 1 st, 2 nd, $\ldots, K$ th lowest cumulative concentration of chemicals from evacuation source point to end point. When designing the 
evacuation route, we only consider evacuating on the paths of the 1 st, 2 nd, ..., Kth lowest cumulative concentration of chemicals instead of evacuating on all the routes.

\subsubsection{Definitions and Characters}

Definition 1. Assume that $P=(1, \ldots, i, j, \ldots, l)$ is a path from the evacuation source point to point $l$ and the arrival time at point $j$ is $t_{j}=t_{i}+t_{i j}$.

Definition 2. The label of point $j$ is $\left(i, t_{j}, m\right)$, and $i$ represents the point on the path prior to point $j, t_{j}$ represents the arrival time at point $j$, and $m$ represents the current stage.

Definition 3. $L_{m}$ represents the point set that is contained in the stage of $m . P_{m-1}(j)$ represents the former point set of stage $m-1$ of point $j \forall j \in L_{m}$ and that is $P_{m-1}(j)=L_{m-1} \cap P(j)$.

Definition 4. Assume that entering arc $e_{i j}$ from point $i$ at time $t$, time $t_{i j}$ is taken to arrive at point $j$ and the concentration of hazardous chemicals at point $i$ is $\operatorname{ppm}(i, t)$ at time $t$, and the concentration of hazardous chemicals at point $j$ is to be $\operatorname{ppm}\left(j, t+t_{i j}\right)$ at time $t+t_{i j}$. Therefore, the concentration of hazardous chemicals that evacuees are exposed to when entering $\operatorname{arc} e_{i j}$ at the time of $t$ is $\left(\operatorname{ppm}(i, t)+\operatorname{ppm}\left(j, t+t_{i j}\right)\right) / 2 \times$ $t_{i j}$, denoted by $\operatorname{ppm}(i, j, t)$.

Definition 5. The initial concentration of dangerous chemicals at the starting point at time $t$ is $\operatorname{ppm}(i, t)+\operatorname{ppm}(i, t-1)$.

Definition 6. Assume that $P=(1, \ldots, i, j, \ldots, l)$ is a path from the evacuation source point to point $l$, the cumulative concentration of hazardous chemicals that the evacuees are exposed to is $\operatorname{PPM}(j, t)=\operatorname{PPM}\left(i, t_{i}\right)+\operatorname{ppm}\left(i, j, t_{i}\right)$ when arriving at point $j$ at time $t$, where $t=t_{i}+t_{i j}$.

Definition 7. The lowest cumulative concentration of hazardous chemicals at point $j$ in $L_{m}$ when arriving at stage $m$ at the time of $t_{j}$ is $\operatorname{PPM}_{m}\left(j, t_{j}\right)$; that is,

$$
\begin{aligned}
\operatorname{PPM}_{m}\left(j, t_{j}\right) \\
=\min _{i \in T(i, t)}\left\{\operatorname{PPM}_{m-1}\left(i, t_{i}\right)+\operatorname{ppm}\left(i, j, t_{i}\right)\right\},
\end{aligned}
$$

where $T\left(i, t_{j}\right)=\left\{i \mid t_{j}=t_{i}+t_{i j}, y_{i}(t) \leq \mathrm{MCN}_{i}, x_{i j}(t) \leq\right.$ $\left.\mathrm{MC}_{i j}, t \in\left[0, t_{j}\right], i \in P_{m-1}(j)\right\}$.

Definition 8. $\operatorname{PPM}^{*}(i)$ represents the lowest cumulative concentration of hazardous chemicals from the evacuation source point to point $i$.

Property 9. One has

$$
\operatorname{PPM}^{*}(i)=\min _{m \in M} \min _{0 \leq t_{i} \leq T} \operatorname{PPM}_{m}\left(i, t_{i}\right)
$$

Property 10. The subpart of the lowest cumulative concentration of hazardous chemicals from the evacuation source point to point $i$ may not be the path of the lowest cumulative concentration of hazardous chemicals.
3.3.2. The Step of the NODS Algorithm. The basic idea of the NODS algorithm is to initially, at each evacuation time $t$, calculate the $K$ shortest paths and their flows according to the concentration of chemicals at each point at each different moment and then evacuate through the $K$ shortest paths that have been calculated, until all of the people at the evacuation source point have been evacuated.

Step 1 (initialization). Let ICS be the number of persons that will be evacuated at the evacuation source point, $\mathrm{MCN}_{i}$ be the maximum capacity of point $i, \mathrm{MC}_{i j}$ be the maximum capacity of arc $e_{i j}$, and $\operatorname{PPM}\left(v_{i}, t\right)$ be the concentration of hazardous chemicals of point $i$ at $t$.

Let the capacity of point $i$ at $t$ be $\mathrm{CN}_{i}(t)=\mathrm{MCN}_{i}$, and the capacity of arc $e_{i j}$ at $t$ be $C_{i j}(t)=\mathrm{MC}_{i j}$;

$$
\text { Let } t_{0}=0 \text {. }
$$

Step 2 (divide phases). Divide each stage according to the number of the arc paths on the evacuation network. Then, we can get the number of the stages $M$. Let $L_{m}$ be the setoff points that belong to stage $m$ and let $m=0$.

Step 3. The start time of the evacuation at the source point is $t=t_{0}$.

Step 4. Search the $K$ shortest paths from source point 1 to point $N$; let $k=1$.

Step 5. Compute the cumulative concentration and the label for every point in stage $m$.

Calculate the minimum cumulative concentration of point $j$ for which the arrival time is $t_{j}$. The minimum cumulative concentration is $\operatorname{PPM}_{m}\left(j, t_{j}\right)=$ $\min _{i \in T\left(i, t_{j}\right)}\left\{\operatorname{PPM}_{m-1}\left(i, t_{i}\right)+\operatorname{PPM}\left(i, j, t_{i}\right)\right\}$ and label $\left(i, t_{j}, m\right)$ to point $j$.

Step 6 (determine whether the stage $m$ is the end). Let $L_{m}=$ $L_{m} \backslash\left\{v_{j}\right\}$. If $L_{m}=\varphi$, then all the points in stage $m$ have been calculated. If $m=M$, then turn to Step 8. Otherwise, let $m=$ $m+1$ and return to Step 5 .

Step 7 (compute the minimum cumulative concentration). The minimum cumulative concentration is $\operatorname{PPM}^{*}(N)=$ $\min _{m} \operatorname{PPM}_{m}\left(N, t_{N}\right)$.

Step 8 (backtrack the shortest path). Backtrack the point according to the label that has the minimum objective value. Then, we can get the $k$ th shortest path for evacuees from source point 1 at $t_{0}$. We denote the $k$ th shortest path from point 1 to point $N$ by $P^{k}=\left\{1, n_{1}^{k}, n_{2}^{k}, \ldots, N\right\}$ and calculate the flow $f^{k}$ and the total time $t^{k}(N)$ of $P^{k}$.

Step 9 (update the evacuation network). If $k=K$, then return to Step 10; else, calculate $\mathrm{MC}_{i j}=\mathrm{MC}_{i j}-f_{a}^{k}, \mathrm{MCN}_{i}=$ $\mathrm{MCN}_{i}-f_{a}^{k}$. If $\mathrm{MC}_{i j}=0$, then delete arc $e_{i j}$ from the network; if $\mathrm{MCN}_{i}=0$, then delete all the former arcs adjacent to point $i$. If the updated network is not connected, return to Step 10. Otherwise, let $k=k+1$, and turn to the Step 4 . 


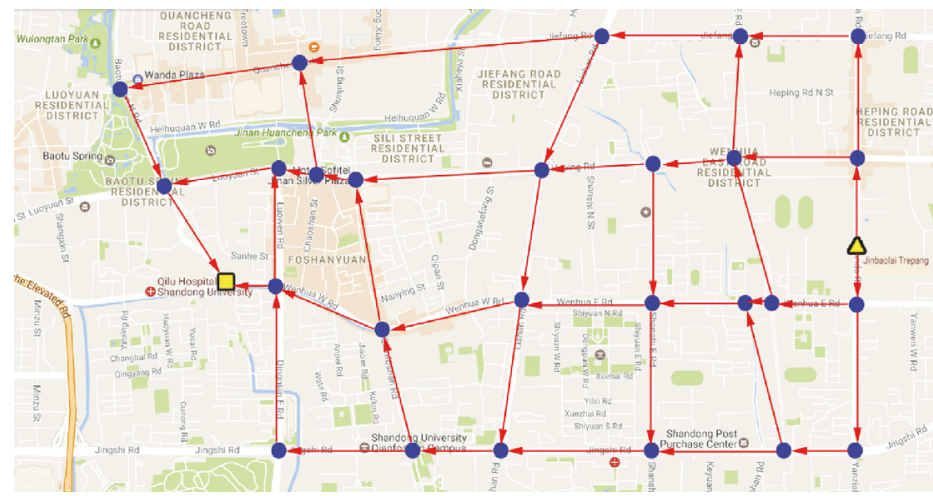

(a) The road map for evacuation

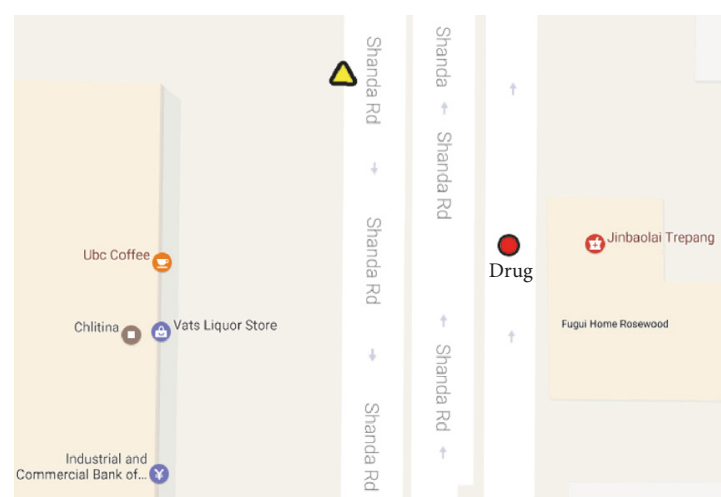

(b) The specific locations of the evacuation origin and the leakage point

FIgURE 3: The evacuation map.

Step 10 (determine whether the evacuation is finished). Check the evacuation source point. If the victims are evacuated, then the algorithm ends. Otherwise, let $t_{0}=t_{0}+1$, and return to Step 3.

\section{Case Study}

This paper uses Jinan as an example to verify the validity and feasibility of the NODS algorithm. For simplicity, we get the number of evacuees from the influenced area and the average influenced population. That is, the number of evacuees equals the influenced area times the average influenced population.

Suppose the tank car, which has a valve diameter of $25 \mathrm{~mm}$ and is loaded with 20 tons of liquid chlorine, had a traffic accident around the Jinbaolai sea cucumber store on Shanda Road at night that damaged the filling valve, causing liquid chlorine to continuously leak from the tank. Assuming the wind is from the west and the wind speed is 5.4 meters/second, we can obtain the influenced area in Lixia district, which is $252,210 \mathrm{~m}^{2}$. The average population of Lixia district is $7466.34 \mathrm{per} / \mathrm{square}$ kilometer. Thus, we can calculate the total number of people who need to be evacuated as 1,884 . In addition, this paper assumes that the transverse distance from the evacuation source point (marked as the triangle in Figure 3 ) to the leakage point is 20 meters, the longitudinal distance is 20 meters, and all people who need to be evacuated are gathered at the evacuation source point. We assume that rescue vehicles are used for evacuation, the departure interval time of each vehicle is 9 seconds, and every 50 evacuees are one unit. Therefore, there are 38 units of victims that need to be evacuated to the emergency end point (marked as square in Figure 3) urgently. The evacuation map, as shown in Figure 3(a), is the road map for the evacuation of the whole evacuation zone. Figure 3(b) shows the specific locations of the evacuation source point and the leakage point.

The evacuation map shown in Figure 3 is represented by the network shown in Figure 4, where (1) is the evacuation source point and its coordinate is $(20,20)$ and $\{28\}$ is the emergency end point and its coordinate is $(3010,150)$. Other points are arc crossing points. The first number in brackets is the maximum capacity of the corresponding arc, and the second number is the time to go through the arc. The concentration of hazardous chemicals at each point depends on time. For ease of calculation, we assume that time is discrete units. In this paper, we take 9 seconds as a unit. There are 38 units of victims at the evacuation source point (1), and we assume that the maximum capacity of all vertices is large enough to accommodate them all. We get the evacuation route by the algorithm that have been mentioned above. The result is shown in Table 2. Among them, the evacuation time is the time when evacuees leave the evacuation source point, and the evacuation completion time is the time when evacuees arrive at the emergency end point. In this section, all computational runs are made using MyEclipse 8.6 on a PC having Intel i3-3217U CPU and 4 GB memory.

From Table 2, we can see that when the number of people who need to be evacuated is 38 units, the shortest paths quantity is $K=3$, and the coordinates of the evacuation source point are $(20,20)$. The three paths, 1-2-4-8-14-22-2627-28, 1-2-7-8-14-22-26-27-28, and 1-3-5-9-13-17-18-23-24-28, are used for evacuation from time 0 to time 7 . From Figure 4, we can see that the three paths selected in every moment are all on the edge of the evacuation network. Their longitudinal distances from the leakage point are all approximately 1000 meters, which is beyond the influence of the leakage. These three routes have the minimum cumulative concentration. Thus, it can be seen that in order to reduce the cumulative damage of evacuees in the entire evacuation process, the vertical direction of the wind should be the priority for evacuation, letting evacuees leave the area that has been affected by the leakage as soon as possible. After the evacuees have left the danger zone, they should then travel along the shortest paths to reach the emergency end point. From Table 2, we can see that it takes 7 units of time, or 63 seconds, to allow all the evacuees to evacuate out of the evacuation source point. It takes 65 units of time, or 585 seconds, for all evacuees to arrive at the emergency end point. As time goes on, the cumulative concentration of chlorine gas is increasing. 


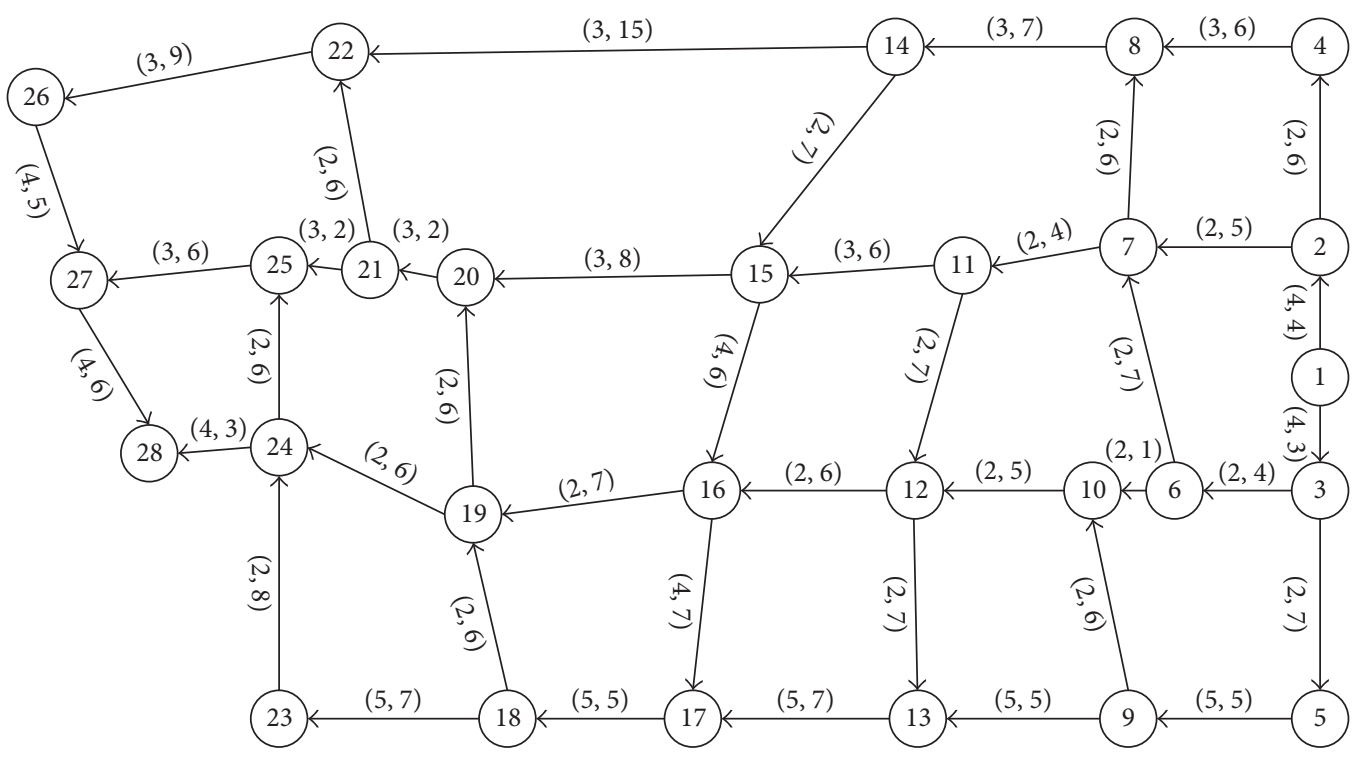

FIGURE 4: The evacuation network.

TABLE 2: Evacuation route results.

\begin{tabular}{|c|c|c|c|c|}
\hline Evacuation time & Evacuation routes & Evacuation unit & $\begin{array}{l}\text { Cumulative concentration } \\
\qquad\left(\mathrm{mg} / \mathrm{m}^{3}\right)\end{array}$ & Evacuation completion time \\
\hline 0 & $1-2-4-8-14-22-26-27-28$ & 2 & 43.80 & 58 \\
\hline 0 & $1-2-7-8-14-22-26-27-28$ & 1 & 43.83 & 57 \\
\hline 0 & $1-3-5-9-13-17-18-23-24-28$ & 2 & 43.91 & 50 \\
\hline 1 & $1-2-4-8-14-22-26-27-28$ & 2 & 85.28 & 59 \\
\hline 1 & $1-2-7-8-14-22-26-27-28$ & 1 & 85.31 & 58 \\
\hline 1 & $1-3-5-9-13-17-18-23-24-28$ & 2 & 85.38 & 51 \\
\hline 2 & $1-2-4-8-14-22-26-27-28$ & 2 & 125.01 & 60 \\
\hline 2 & $1-2-7-8-14-22-26-27-28$ & 1 & 125.03 & 59 \\
\hline 2 & $1-3-5-9-13-17-18-23-24-28$ & 2 & 125.11 & 52 \\
\hline 3 & $1-2-4-8-14-22-26-27-28$ & 2 & 163.24 & 61 \\
\hline 3 & $1-2-7-8-14-22-26-27-28$ & 1 & 163.26 & 60 \\
\hline 3 & $1-3-5-9-13-17-18-23-24-28$ & 2 & 163.33 & 53 \\
\hline 4 & $1-2-4-8-14-22-26-27-28$ & 2 & 200.14 & 62 \\
\hline 4 & $1-2-7-8-14-22-26-27-28$ & 1 & 200.16 & 61 \\
\hline 4 & $1-3-5-9-13-17-18-23-24-28$ & 2 & 200.23 & 54 \\
\hline 5 & $1-2-4-8-14-22-26-27-28$ & 2 & 235.86 & 63 \\
\hline 5 & $1-2-7-8-14-22-26-27-28$ & 1 & 235.88 & 62 \\
\hline 5 & $1-3-5-9-13-17-18-23-24-28$ & 2 & 235.96 & 55 \\
\hline 6 & $1-2-4-8-14-22-26-27-28$ & 2 & 270.53 & 64 \\
\hline 6 & $1-2-7-8-14-22-26-27-28$ & 1 & 270.55 & 63 \\
\hline 6 & $1-3-5-9-13-17-18-23-24-28$ & 2 & 270.63 & 56 \\
\hline 7 & $1-2-4-8-14-22-26-27-28$ & 2 & 304.26 & 65 \\
\hline 7 & $1-2-7-8-14-22-26-27-28$ & 1 & 304.27 & 64 \\
\hline
\end{tabular}

The highest cumulative concentration reaches approximately $304.27 \mathrm{mg} / \mathrm{m}^{3}$ at time 7 . This concentration will cause serious physical injury, but it is not a lethal concentration of chlorine gas. After 100 tests, the average program execution time of our algorithm is 20.2 seconds, and change in program execution time of each experiment is shown in Figure 5.
Next, we change the evacuation scale, the shortest path quantity, and evacuation source point coordinates (the distance from the evacuation source point to the leakage point) to create different scenarios. Then, we solve the different scenarios with the algorithm that has been mentioned above and analyze the results. 


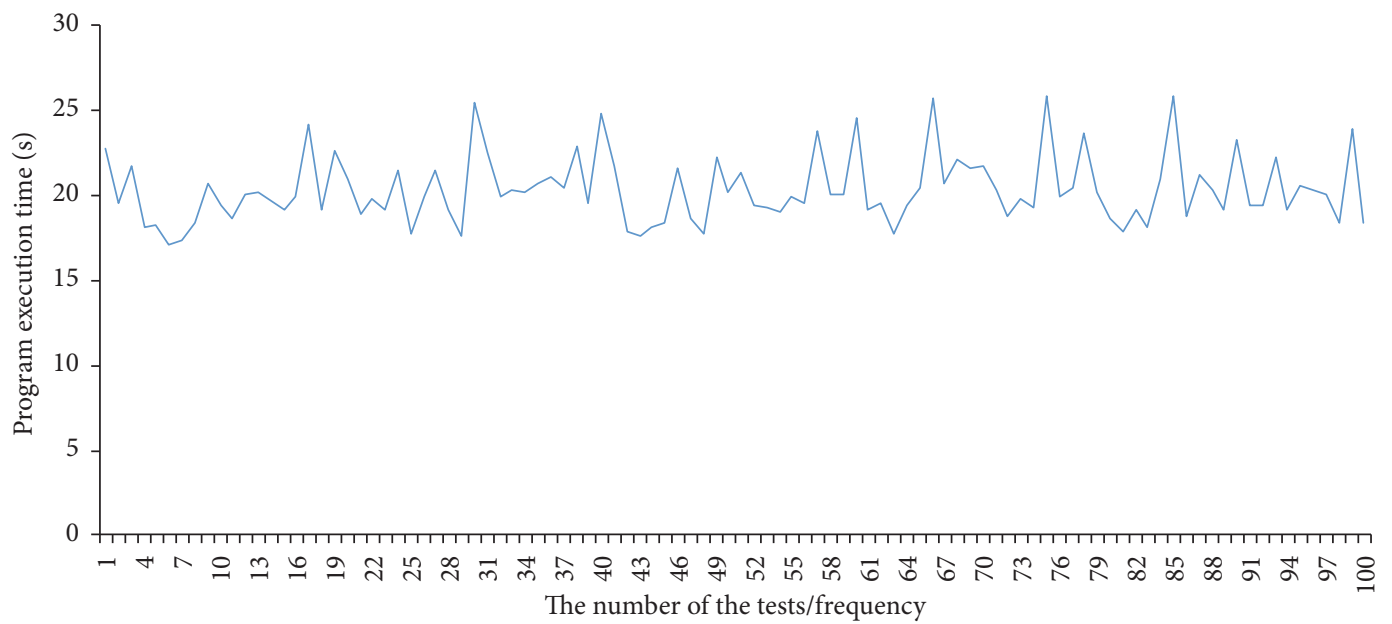

Figure 5: The diagram of program execution time in 100 tests.

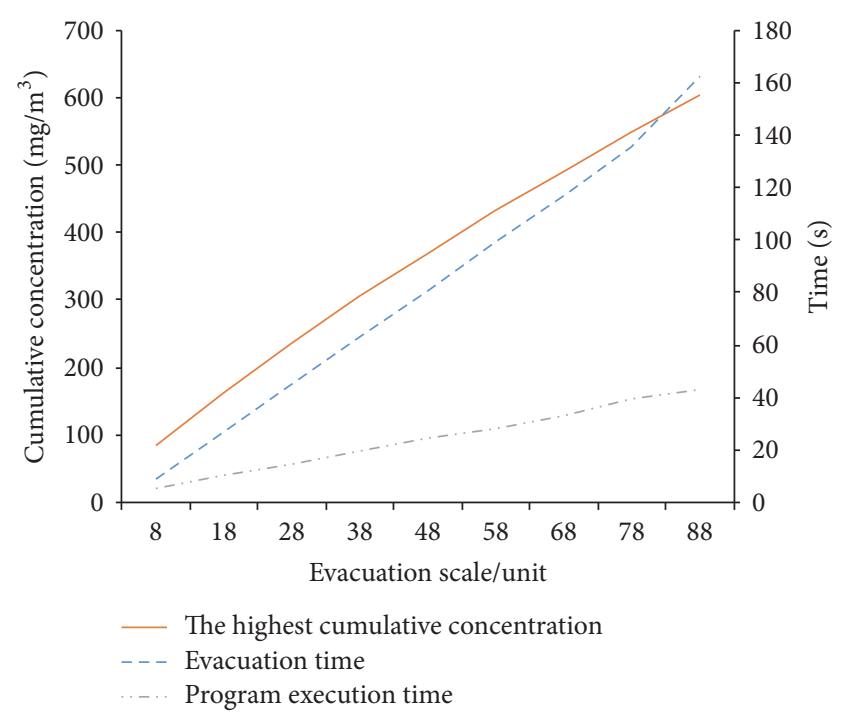

FIGURE 6: The results of different evacuation scales.

\subsection{Comparing the Calculation Results of Different Evacuation} Scales. We take 50 evacuees as one unit of evacuees, the shortest path quantity to be $K=3$, and the evacuation source point coordinate to be $(20,20)$ as a constant condition. We change the evacuation scale to create different scenarios and calculate them with the algorithm. Among them, 8, 18, and 28 units are considered small-scale, 38,48 , and 58 units are considered middle-scale, and 68,78 , and 88 units are considered large-scale. The calculated results are shown in Table 3. The evacuation time is the time when the evacuees leave the evacuation source point. All the time units are in seconds.

To analyze the influence of different evacuation scales on the result, we use the line chart to display the calculation results in Table 3, as shown in Figure 6.

From Figure 6, we can see that when the shortest path quantity and the evacuation source point coordinate are constant, with the increase of the evacuation scale, the evacuation time curve, the highest cumulative concentration curve, and the program execution time curve all increase with a linear growth trend. Compared to the program execution time curve, the evacuation time curve and the highest cumulative concentration curve show a relatively fast growth trend. This is because in the evacuation process with different evacuation scales, the shortest paths selected are the same in every moment, and the number of leaving evacuees is fixed in every moment. Therefore, the greater the evacuation scales, the longer the evacuation time. In every moment, the evacuees who stay in the evacuation source point will get more damaged with the passage of time, so the highest cumulative concentration will increase with the increase in evacuation time. The program execution time curve shows a relatively smooth linear growth trend, thus indicating that the algorithm is efficient and stable and demonstrates good performance. From what has been discussed above, when the shortest path quantity and the evacuation source point coordinate are constant, we should try to increase the number of evacuees on every path, such as using large rescue vehicles instead of small rescue vehicles, and clear the evacuation routes in order to improve the traffic load so that we can shorten the evacuation time and reduce the highest cumulative concentration.

\subsection{Comparing the Calculation Results of Different Shortest} Path Quantity. We take 50 evacuees to be one unit, the evacuation scale to be 38 units, and the evacuation source point coordinate to be $(20,20)$ as a constant condition. We change the shortest path quantity $K$ to create different scenarios and calculate them with the algorithm. Because the evacuation routes are limited and the traffic load of every path is limited at the same time, we can only find 6 shortest paths at most. Table 4 shows the calculation results when the shortest path quantity $K$ takes values of 1, 2, 3, 4, 5, and 6 . The evacuation time is the time when the evacuees leave the evacuation source point. All time units are seconds.

To analyze the influence of different shortest path quantity on the result, we use the line chart to display the calculation results in Table 4, as shown in Figure 7. 
TABLE 3: The calculative results of different evacuation scales.

\begin{tabular}{|c|c|c|c|c|}
\hline $\begin{array}{l}\text { Evacuation } \\
\text { scale (units) }\end{array}$ & Evacuation routes & Evacuation time (s) & $\begin{array}{l}\text { The highest cumulative } \\
\text { concentration } \\
\left(\mathrm{mg} / \mathrm{m}^{3}\right)\end{array}$ & Program execution time (s) \\
\hline 8 & $\begin{array}{c}1-2-4-8-14-22-26-27-28 \\
1-2-7-8-14-22-26-27-28 \\
1-3-5-9-13-17-18-23-24-28\end{array}$ & 9 & 85.31 & 5.6 \\
\hline 18 & $\begin{array}{c}1-2-4-8-14-22-26-27-28 \\
1-2-7-8-14-22-26-27-28 \\
1-3-5-9-13-17-18-23-24-28\end{array}$ & 27 & 163.26 & 10.1 \\
\hline 28 & $\begin{array}{c}1-2-4-8-14-22-26-27-28 \\
1-2-7-8-14-22-26-27-28 \\
1-3-5-9-13-17-18-23-24-28\end{array}$ & 45 & 235.89 & 14.9 \\
\hline 38 & $\begin{array}{c}1-2-4-8-14-22-26-27-28 \\
1-2-7-8-14-22-26-27-28 \\
1-3-5-9-13-17-18-23-24-28\end{array}$ & 63 & 304.27 & 19.8 \\
\hline 48 & $\begin{array}{c}1-2-4-8-14-22-26-27-28 \\
1-2-7-8-14-22-26-27-28 \\
1-3-5-9-13-17-18-23-24-28\end{array}$ & 81 & 369.16 & 24.8 \\
\hline 58 & $\begin{array}{c}1-2-4-8-14-22-26-27-28 \\
1-2-7-8-14-22-26-27-28 \\
1-3-5-9-13-17-18-23-24-28\end{array}$ & 99 & 431.09 & 28.3 \\
\hline 68 & $\begin{array}{c}1-2-4-8-14-22-26-27-28 \\
1-2-7-8-14-22-26-27-28 \\
1-3-5-9-13-17-18-23-24-28\end{array}$ & 117 & 490.47 & 32.8 \\
\hline 78 & $\begin{array}{c}1-2-4-8-14-22-26-27-28 \\
1-2-7-8-14-22-26-27-28 \\
1-3-5-9-13-17-18-23-24-28\end{array}$ & 135 & 547.61 & 39.2 \\
\hline 88 & $\begin{array}{c}1-2-4-8-14-22-26-27-28 \\
1-2-7-8-14-22-26-27-28 \\
1-3-5-9-13-17-18-23-24-28\end{array}$ & 162 & 602.75 & 43.2 \\
\hline
\end{tabular}

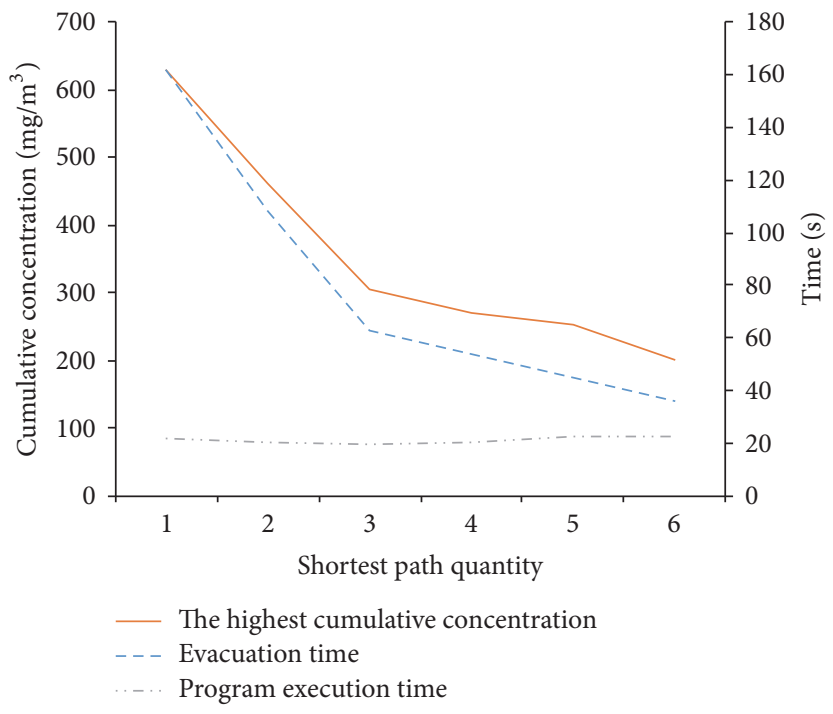

(a) The comprehensive comparison of every indicator

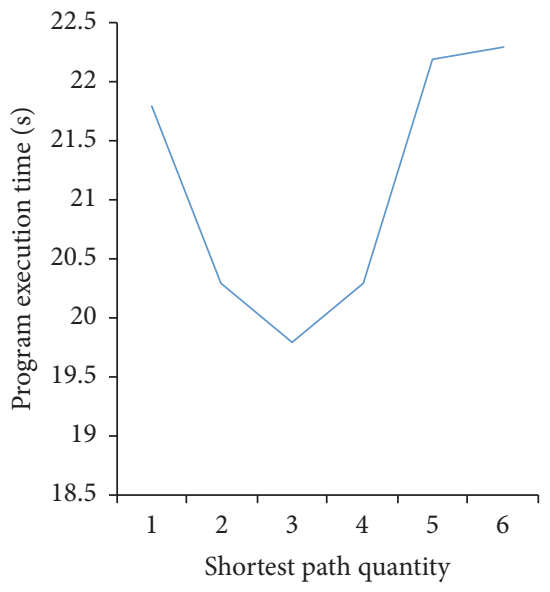

(b) Program execution time curve

FIGURE 7: The results of different shortest path quantity. 
TABLE 4: The calculative results of different shortest path quantity.

\begin{tabular}{|c|c|c|c|c|}
\hline $\begin{array}{l}\text { Shortest path } \\
\text { quantity }\end{array}$ & Evacuation routes & Evacuation time (s) & $\begin{array}{l}\text { The highest cumulative } \\
\text { concentration } \\
\left(\mathrm{mg} / \mathrm{m}^{3}\right)\end{array}$ & Program execution time (s) \\
\hline 1 & $1-2-4-8-14-22-26-27-28$ & 162 & 629.63 & 21.8 \\
\hline 2 & $\begin{array}{l}1-2-4-8-14-22-26-27-28 \\
1-2-7-8-14-22-26-27-28\end{array}$ & 108 & 461.06 & 20.3 \\
\hline 3 & $\begin{array}{c}1-2-4-8-14-22-26-27-28 \\
1-2-7-8-14-22-26-27-28 \\
1-3-5-9-13-17-18-23-24-28\end{array}$ & 63 & 304.27 & 19.8 \\
\hline 4 & $\begin{array}{c}1-2-4-8-14-22-26-27-28 \\
1-2-7-8-14-22-26-27-28 \\
1-3-5-9-13-17-18-23-24-28 \\
1-2-7-11-15-20-21-25-27-28\end{array}$ & 54 & 270.54 & 20.3 \\
\hline 5 & $\begin{array}{c}1-2-4-8-14-22-26-27-28 \\
1-2-7-8-14-22-26-27-28 \\
1-3-5-9-13-17-18-23-24-28 \\
1-2-7-11-15-20-21-25-27-28 \\
1-3-6-7-11-15-16-19-24-28\end{array}$ & 45 & 235.89 & 22.2 \\
\hline 6 & $\begin{array}{c}1-2-4-8-14-22-26-27-28 \\
1-2-7-8-14-22-26-27-28 \\
1-3-5-9-13-17-18-23-24-28 \\
1-2-7-11-15-20-21-25-27-28 \\
1-3-6-7-11-15-16-19-24-28 \\
1-3-6-10-12-16-19-24-28\end{array}$ & 36 & 200.47 & 22.3 \\
\hline
\end{tabular}

We can see from Figure 7 that as the shortest path quantity increases, the evacuation time curve and the highest cumulative concentration curve show a downward trend. The shortest path quantity $K=3$ is a turning point. When $K<3$, the downward slope is big, and the curves are rapidly declining. When $K>3$, the downward slope is diminishing and the decline speed is also slowing down, which shows the shortest path quantity has an influence on the evacuation time and the highest cumulative concentration, but the influence reduces as the shortest path quantity increases. From Figure 7(b), we can see that the program execution time curve has low middle and high ends, which suggests that a larger shortest path quantity or a smaller shortest path quantity will reduce the efficiency of the algorithm. From what has been discussed above, the shortest path quantity should be taken as 3 or 4 . This can ensure that the evacuation time, the highest cumulative concentration, and the program execution time all fall in an ideal range.

\subsection{Comparing the Calculation Results of Different Evacuation} Source Point Coordinates. In this case, we take every 50 evacuees to be one unit, the evacuation scale to be 38 units, and the shortest path quantity to be $K=3$ as a constant condition. We change the evacuation source point coordinates to create different scenarios and calculate them with the algorithm. According to the shown in Figure 1, we select $(20,10),(20,15),(20,20),(20,25),(20,30),(20,35)$, and $(20,40)$ as the coordinates of the evacuation source point. The calculation results are shown in Table 5. The evacuation time is the time when the evacuees leave the evacuation source point. All time units are in seconds.
To analyze the influence of different evacuation source point coordinates on the result, we use the line chart to display the calculated results in Table 5, as shown in Figure 8.

In this case, the evacuation scale and the shortest path quantity are held constant, making the evacuation source point abscissa constant. Changing the evacuation source point ordinate, from Figure 8(a), we can see that the evacuation time curve shows a horizontal trend. From Table 5, we can see that changing the evacuation source point coordinates has no effect on selecting the shortest routes. It can be seen, with different evacuation source point coordinates, that the number of evacuees who leave the evacuation source point is always the same at every moment, so the evacuation time is also the same. This suggests that changing the evacuation source point coordinate has no significant effect on the evacuation time. As the evacuation source point coordinates change, the program execution curve has a certain fluctuation, but the range is just 1.4 seconds. This suggests that changing the evacuation source point coordinate has no significant effect on program execution time. As the evacuation source point abscissa increases, the highest cumulative concentration curve declines rapidly towards zero. This suggests that changing the evacuation source point coordinates has a significant effect on the highest cumulative concentration of the whole evacuation process. When the evacuation source point abscissa is a constant, the farther the ordinate and the lower the concentration of hazardous chemicals at the evacuation source point. This makes the highest cumulative concentration lower in the whole evacuation process. From Figure 8, we can see that as the evacuation source point ordinates increase, the disparity of highest cumulative concentration between different evacuation source point abscissas 
TABLE 5: The calculative results of different evacuation source point coordinates.

\begin{tabular}{|c|c|c|c|c|}
\hline $\begin{array}{l}\text { Evacuation } \\
\text { source } \\
\text { point coordinate }\end{array}$ & Evacuation routes & Evacuation time (s) & $\begin{array}{l}\text { The highest cumulative } \\
\text { concentration } \\
\left(\mathrm{mg} / \mathrm{m}^{3}\right)\end{array}$ & Program execution time (s) \\
\hline$(20,10)$ & $\begin{array}{c}1-2-4-8-14-22-26-27-28 \\
1-2-7-8-14-22-26-27-28 \\
1-3-5-9-13-17-18-23-24-28\end{array}$ & 63 & 12816.29 & 19.2 \\
\hline$(20,15)$ & $\begin{array}{c}1-2-4-8-14-22-26-27-28 \\
1-2-7-8-14-22-26-27-28 \\
1-3-5-9-13-17-18-23-24-28\end{array}$ & 63 & 2696.45 & 19.8 \\
\hline$(20,20)$ & $\begin{array}{c}1-2-4-8-14-22-26-27-28 \\
1-2-7-8-14-22-26-27-28 \\
1-3-5-9-13-17-18-23-24-28\end{array}$ & 63 & 304.27 & 19.9 \\
\hline$(20,25)$ & $\begin{array}{c}1-2-4-8-14-22-26-27-28 \\
1-2-7-8-14-22-26-27-28 \\
1-3-5-9-13-17-18-23-24-28\end{array}$ & 63 & 18.59 & 20.4 \\
\hline$(20,30)$ & $\begin{array}{c}1-2-4-8-14-22-26-27-28 \\
1-2-7-8-14-22-26-27-28 \\
1-3-5-9-13-17-18-23-24-28\end{array}$ & 63 & 0.81 & 20.6 \\
\hline$(20,35)$ & $\begin{array}{c}1-2-4-8-14-22-26-27-28 \\
1-2-7-8-14-22-26-27-28 \\
1-3-5-9-13-17-18-23-24-28\end{array}$ & 63 & 0.22 & 20.6 \\
\hline$(20,40)$ & $\begin{array}{l}1-2-4-8-14-22-26-27-28 \\
1-2-7-8-14-22-26-27-28 \\
1-3-5-9-13-17-18-23-24-28\end{array}$ & 63 & 0.21 & 20.3 \\
\hline
\end{tabular}

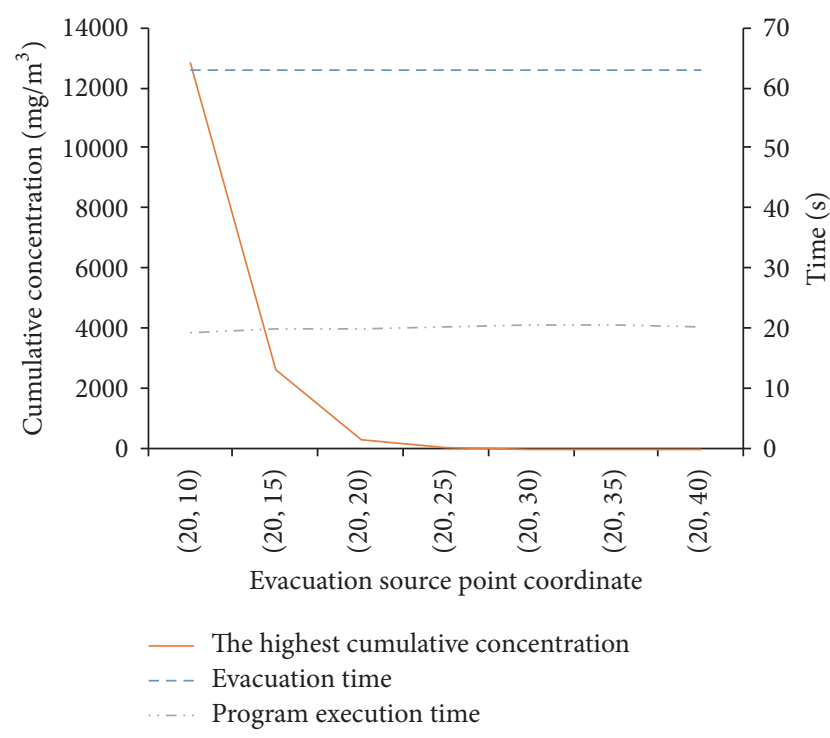

(a) The comprehensive comparison of every indicator

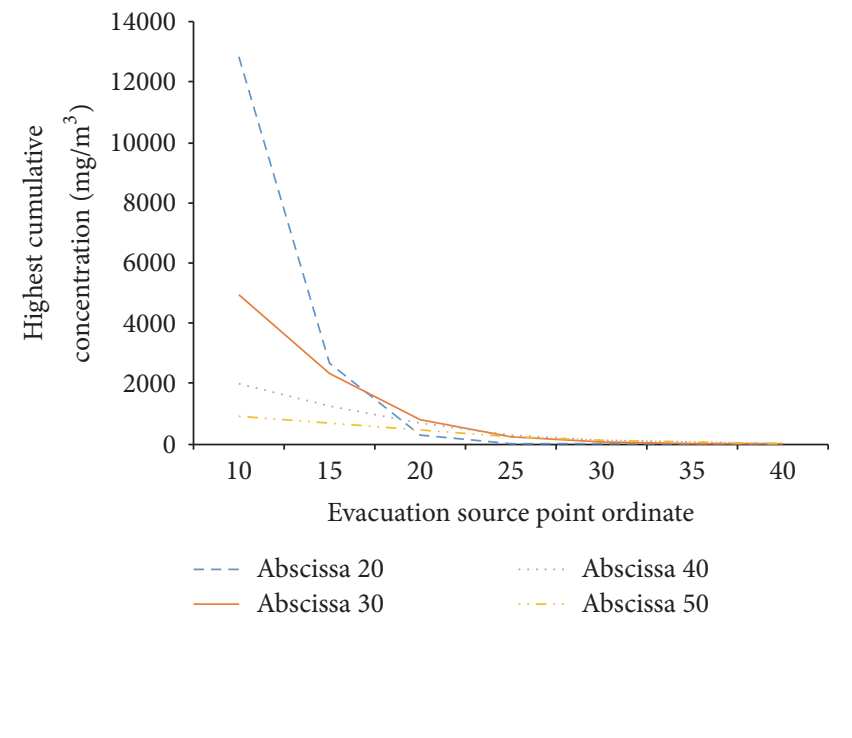

(b) The highest cumulative concentration of different evacuation source point abscissa

FIGURE 8: The results of different evacuation source point coordinates.

decreases, and the speed of decrease is faster and faster. Combined with Figure 1, we can see that the influence distance of the hazardous chemicals leakage in the downwind direction is much longer than that in the vertical direction of the wind, so we can know that the influence of the evacuation source point ordinates on the highest cumulative concentration is more significant than that of the abscissa. When we choose the evacuation source point, we should increase the ordinate to make the source point further away from the leakage point in the longitudinal direction, thereby reducing the highest cumulative concentration in the whole evacuation process.

\section{Conclusions}

Emergency evacuation is one of the key steps of emergency rescue. It is of great significance to study the evacuation 
problem in order to decrease the harm of emergency accidents and disasters. However, different from other disasters and accidents, hazardous chemical accidents may diffuse their damage over a wide area. In this paper, considering the dynamic changes of hazardous chemicals' concentration, we establish a mixed-integer programming model for the emergency evacuation of hazardous chemical accidents that aims to minimize the concentration of hazardous chemicals to which people are exposed during the entire evacuation process. Then, based on network optimization, we design the NODS algorithm that can calculate evacuation plans following hazardous chemical accidents. The numerical examples illustrate the feasibility and effectiveness of NODS algorithm. Finally, we explore the key factors affecting the evacuation process through different scenarios. In future research, we will further consider hazardous chemical accidents with multi-source points.

\section{Conflicts of Interest}

The authors declare that they have no conflicts of interest.

\section{Acknowledgments}

The authors would like to thank the Qilu Young Scholars and Tang Scholars of Shandong University for financial and technical support. This paper was partially supported by the National Natural Science Foundation of China (NSFC) (Grants nos. 71201093 and 71571111), the Independent Innovation Foundation of Shandong University, and the Fundamental Research Funds of Shandong University.

\section{References}

[1] W. H. Hamacher and S. A. Tjandra, Mathematical Modeling of Evacuation Problems A State of The Art, Pedestrian and evacuation dynamics, Springer-Verlag, Berlin, Germany, 2002, 227-266.

[2] P. Murray-Tuite and B. Wolshon, "Evacuation transportation modeling: an overview of research, development, and practice," Transportation Research Part C: Emerging Technologies, vol. 27, pp. 25-45, 2013.

[3] T. J. Cova and J. P. Johnson, "A network flow model for lanebased evacuation routing," Transportation Research Part A: Policy and Practice, vol. 37, no. 7, pp. 579-604, 2003.

[4] C. Xie and M. A. Turnquist, "Lane-based evacuation network optimization: an integrated Lagrangian relaxation and tabu search approach," Transportation Research Part C: Emerging Technologies, vol. 19, no. 1, pp. 40-63, 2011.

[5] Z. Fang, Q. Li, Q. Li, L. D. Han, and S.-L. Shaw, "A spacetime efficiency model for optimizing intra-intersection vehiclepedestrian evacuation movements," Transportation Research Part C: Emerging Technologies, vol. 31, pp. 112-130, 2013.

[6] G. J. Lim, S. Zangeneh, M. Reza Baharnemati, and T. Assavapokee, "A capacitated network flow optimization approach for short notice evacuation planning," European Journal of Operational Research, vol. 223, no. 1, pp. 234-245, 2012.

[7] Y. Hadas and A. Laor, "Network design model with evacuation constraints," Transportation Research Part A: Policy and Practice, vol. 47, pp. 1-9, 2013.
[8] J.-B. Sheu and C. Pan, "A method for designing centralized emergency supply network to respond to large-scale natural disasters," Transportation Research Part B: Methodological, vol. 67, pp. 284-305, 2014.

[9] J. Duanmu, M. Chowdhury, K. Taaffe, and C. Jordan, "Buffering in evacuation management for optimal traffic demand distribution," Transportation Research Part E: Logistics and Transportation Review, vol. 48, no. 3, pp. 684-700, 2012.

[10] K. Uchida, "Estimating the value of travel time and of travel time reliability in road networks," Transportation Research Part B: Methodological, vol. 66, pp. 129-147, 2014.

[11] X. Zhang and G.-L. Chang, "A dynamic evacuation model for pedestrian-vehicle mixed-flow networks," Transportation Research Part C: Emerging Technologies, vol. 40, pp. 75-92, 2014.

[12] M. Snelder, H. J. van Zuylen, and L. H. Immers, "A framework for robustness analysis of road networks for short term variations in supply," Transportation Research Part A: Policy and Practice, vol. 46, no. 5, pp. 828-842, 2012.

[13] B. Y. Chen, W. H. K. Lam, A. Sumalee, Q. Li, and Z.-C. $\mathrm{Li}$, "Vulnerability analysis for large-scale and congested road networks with demand uncertainty," Transportation Research Part A: Policy and Practice, vol. 46, no. 3, pp. 501-516, 2012.

[14] M. G. H. Bell, A. Fonzone, and C. Polyzoni, "Depot location in degradable transport networks," Transportation Research Part B: Methodological, vol. 66, pp. 148-161, 2014.

[15] W. Zhang, J. Zhou, Y. Liu, X. Chen, and C. Wang, "Emergency evacuation planning against dike-break flood: a GIS-based DSS for flood detention basin of Jingjiang in central China," Natural Hazards, vol. 81, no. 2, pp. 1283-1301, 2016.

[16] W. Yin, P. Murray-Tuite, S. V. Ukkusuri, and H. Gladwin, "An agent-based modeling system for travel demand simulation for hurricane evacuation," Transportation Research Part C: Emerging Technologies, vol. 42, no. 2, pp. 44-59, 2014.

[17] L. Zhang, Y. Wang, H. Shi, and L. Zhang, "Modeling and analyzing 3D complex building interiors for effective evacuation simulations," Fire Safety Journal, vol. 53, pp. 1-12, 2012.

[18] T. Nishino, T. Tanaka, and A. Hokugo, "An evaluation method for the urban post-earthquake fire risk considering multiple scenarios of fire spread and evacuation," Fire Safety Journal, vol. 54, pp. 167-180, 2012.

[19] D. Alvear, O. Abreu, A. Cuesta, and V. Alonso, "A new method for assessing the application of deterministic or stochastic modelling approach in evacuation scenarios," Fire Safety Journal, vol. 65, pp. 11-18, 2014.

[20] G.-Y. Wu and H.-Ch. Huang, "Modeling the emergency evacuation of the high rise building based on the control volume model," Safety Science, vol. 73, no. 5, pp. 62-72, 2015.

[21] C. Wang and J. Wang, "Risk-Field Based Modeling for Pedestrian Emergency Evacuation Combined with Alternative Route Strategy," Mathematical Problems in Engineering, vol. 2017, pp. 1-10, 2017.

[22] S. C. Pursals and F. G. Garzón, "Optimal building evacuation time considering evacuation routes," European Journal of Operational Research, vol. 192, no. 2, pp. 692-699, 2009.

[23] X. Zhang, X. Li, and G. Hadjisophocleous, "A probabilistic occupant evacuation model for fire emergencies using Monte Carlo methods," Fire Safety Journal, vol. 58, no. 5, pp. 15-24, 2013.

[24] E. Ronchi, E. D. Kuligowski, R. D. Peacock, and P. A. Reneke, "A probabilistic approach for the analysis of evacuation movement data," Fire Safety Journal, vol. 63, pp. 69-78, 2014. 
[25] C.-H. Wu and L.-C. Chen, "3D spatial information for firefighting search and rescue route analysis within buildings," Fire Safety Journal, vol. 48, pp. 21-29, 2012.

[26] A. Bhushan and N. L. Sarda, "Modeling of building evacuation using ladders," Fire Safety Journal, vol. 55, pp. 126-138, 2013.

[27] M. Siddiqui, S. Jayanti, and T. Swaminathan, "CFD analysis of dense gas dispersion in indoor environment for risk assessment and risk mitigation," Journal of Hazardous Materials, vol. 209210, pp. 177-185, 2012.

[28] M. Verma, V. Verter, and N. Zufferey, "A bi-objective model for planning and managing rail-truck intermodal transportation of hazardous materials," Transportation Research Part E: Logistics and Transportation Review, vol. 48, no. 1, pp. 132-149, 2012.

[29] A. C. Y. Li, L. Nozick, N. Xu, and R. Davidson, "Shelter location and transportation planning under hurricane conditions," Transportation Research Part E: Logistics and Transportation Review, vol. 48, no. 4, pp. 715-729, 2012.

[30] M. Najafi, K. Eshghi, and W. Dullaert, "A multi-objective robust optimization model for logistics planning in the earthquake response phase," Transportation Research Part E: Logistics and Transportation Review, vol. 49, no. 1, pp. 217-249, 2013.

[31] D. R. Bish and H. D. Sherali, "Aggregate-level demand management in evacuation planning," European Journal of Operational Research, vol. 224, no. 1, pp. 79-92, 2013.

[32] Y. Shen, Q. Wang, W. Yan, and J. Sun, "An evacuation model coupling with toxic effect for chemical industrial park," Journal of Loss Prevention in the Process Industries, vol. 33, pp. 258-265, 2015.

[33] Z. X. Wang, eakage simulation Analysis and Diffusion model optimization of Hazardous Chemicals, Dalian University of Technology, 2016, (in Chinese).

[34] Z. X. Mo, T. X. Wu, F. Xie, and W. H. Song, "Simulation and the emergency measures study of the transient leakage of liquid ammonia transient based on MATLAB," Acta Scientiarum Naturalium Universitatis Nankaien, vol. 4, pp. 1-5, 2014, (in Chinese). 


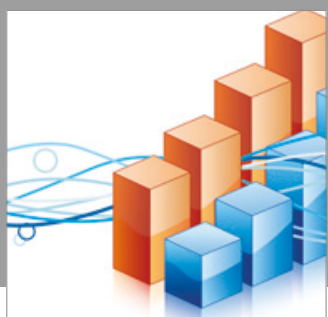

Advances in

Operations Research

vatersals

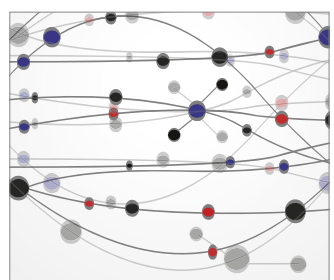

\section{The Scientific} World Journal
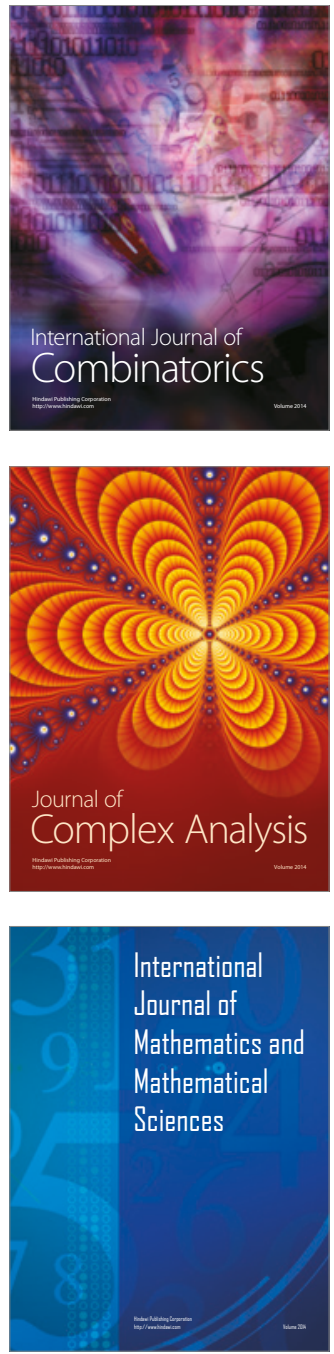
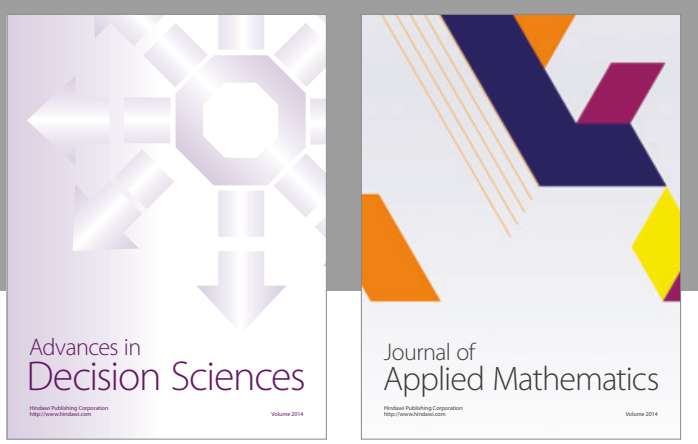

Algebra

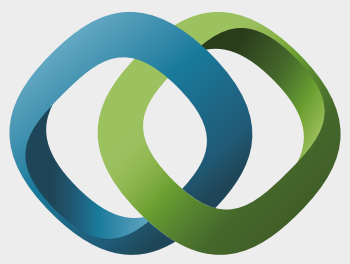

\section{Hindawi}

Submit your manuscripts at

https://www.hindawi.com
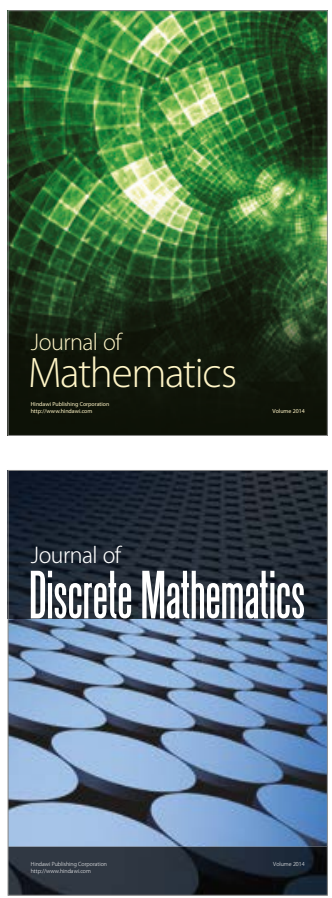

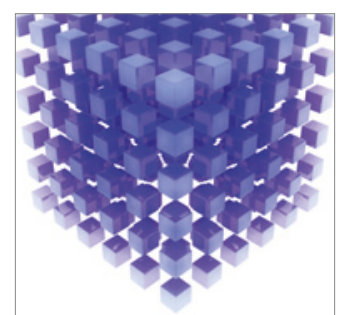

Mathematical Problems in Engineering
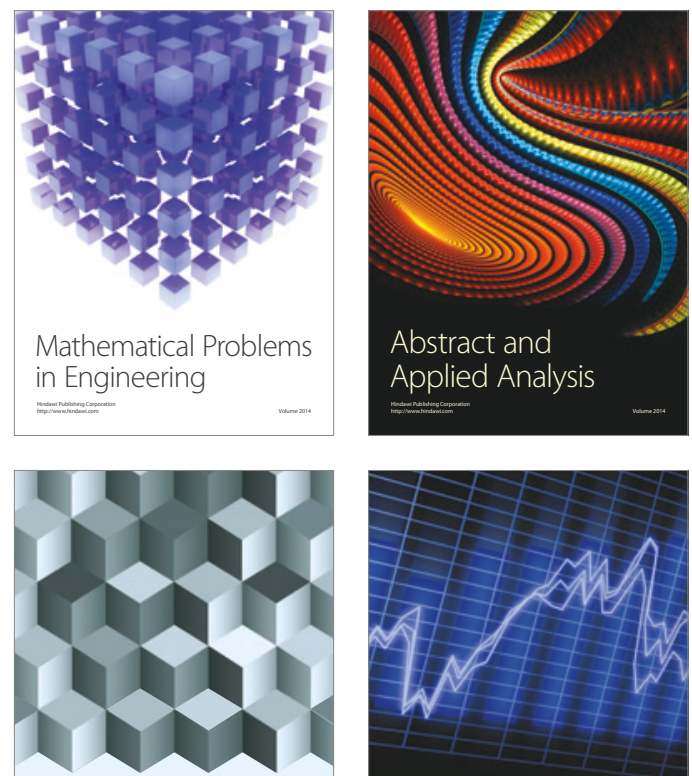

Journal of

Function Spaces

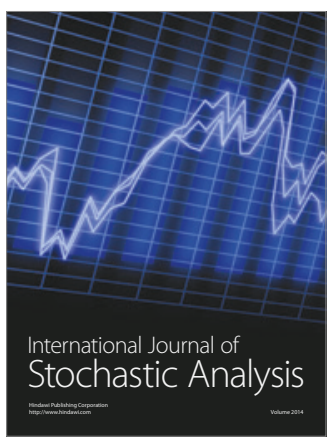

Probability and Statistics
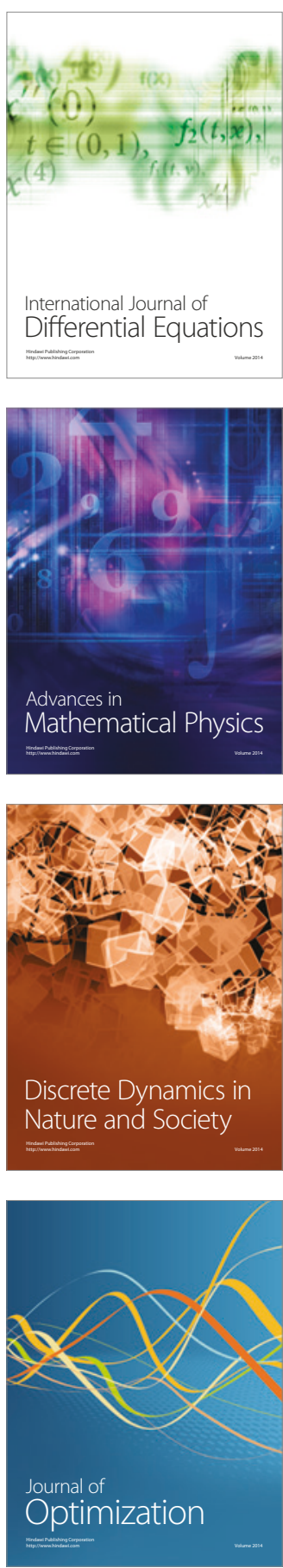